\title{
Development of Transdermal Patches for the Delivery of Chlorpheniramine in Infants using Hypromellose and Cassava Starch Composite Polymers
}

\author{
Agubata Chukwuma 0. *1, Nta Blessing B. ${ }^{1}$, Onunkwo Godswill C. ${ }^{1}$, Joshua Parker E. ${ }^{2}$, Ofoefule Sabinus I. ${ }^{\text {, }}$ \\ Onoja Remigius I. ${ }^{3}$ \\ *1 Department of Pharmaceutical Technology and Industrial Pharmacy, University of Nigeria Nsukka \\ 2 Department of Biochemistry, University of Nigeria Nsukka \\ ${ }^{3}$ Department of Veterinary Pathology and Microbiology, University of Nigeria Nsukka
}

\begin{abstract}
Background: Chlorpheniramine is an antihistamine that is used in the treatment of rhinitis and other allergies. Objectives: The objectives of this research was to develop and evaluate transdermal patches for improved delivery of chlorpheniramine in infants using hypromellose and cassava starch composite polymers. Methods: Chlorpheniramine transdermal patches were formulated by solvent casting method using varying amounts of hypromellose (hydroxypropyl methylcellulose), cassava starch and polyethylene glycol 4000 . The formulated transdermal patches were characterized by Fourier Transform Infra-red Spectroscopy (FT-IR), folding endurance, elongation breaking test, percentage moisture uptake/loss and ex vivo permeation studies. Results: The spectra showed no chemical interaction between the ingredients. The transdermal patches showed elastic qualities and high folding endurance. Patches with consistently high moisture uptake (around 40\%) were observed to contain high concentration of cassava starch while those with higher amounts of HPMC lost more water (around 35\%). The ex vivo study showed efficient permeation and flux for the target purpose. Conclusion: Transdermal patches may be used to deliver low dose chlorpheniramine drug through the skin possibly soft and thin infant skin.
\end{abstract}

Keywords: Transdermal; permeation; flux; allergy; chlorpheniramine

Article Info: Received 08 April 2020; Review Completed 09 June 2020; Accepted 18 June 2020; Available online 15 July 2020

Cite this article as:

Agubata CO, Nta BB, Onunkwo GC, Joshua PE, Ofoefule SI, Onoja RI, Development of Transdermal Patches for the Delivery of Chlorpheniramine in Infants using Hypromellose and Cassava Starch Composite Polymers, Journal of Drug Delivery and Therapeutics. 2020; 10(4):125-132 http://dx.doi.org/10.22270/jddt.v10i4.4163

*Address for Correspondence:

Agubata Chukwuma O., Department of Pharmaceutical Technology and Industrial Pharmacy, University of Nigeria Nsukka

\section{INTRODUCTION}

Chlorpheniramine is a first generation, oral sedating antihistamine (H1-blocker) of the alkylamine class used in the treatment of rhinitis and other allergies. It is an anticholinergic antihistamine. The half-life in children is around $13 \mathrm{~h}^{1}$, whereas in adults it is approximately $20 \mathrm{~h}$ and is mainly eliminated after metabolism to monodesmethyl and didesmethyl compounds 2 . The drug is largely inactivated in the liver and the metabolites excreted in the urine. The continuous treatment of infants of these allergies may require frequent administration of chlorpheniramine and transdermal administration would provide a convenient, safer and more effective route with bypass of first-pass metabolism in liver.

Transdermal drug delivery systems are self-contained, discrete dosage forms which are actually patches 3 that when applied to the intact skin, deliver any loaded drug through

ISSN: 2250-1177 the skin at a controlled rate to the systemic circulation ${ }^{4}$. This set-up allows a pre-calculated amount of drug to be delivered at pre-designed and reproducible rate through the skin ${ }^{3}$. Transdermal drug administration is non-invasive and therefore avoids any interference with body barrier or disruption of physiological barriers such as the skin. Influx of drug into the human blood system can be promptly interrupted simply by removal of the patch if toxicity is observed in any form such as reactions or discomfort. This mode of drug administration improves compliance.

Chlorpheniramine is a low dose drug and the skin of infants is sufficiently tender, thin and weak to encourage passage of low dose drugs which explains the rational for engaging in this study.

The objective of this research is to prepare, optimize and characterize transdermal patches for the delivery of 
chlorpheniramine in infants using hypromellose and cassava starch composite polymers.

\section{MATERIALS AND METHODS}

\section{Materials}

Chlorpheniramine (Juhel, Nigeria), HPMC (Qualikems, India), Cassava starch (extracted in Pharm Tech Lab, UNN), PEG 4000, Propylene glycol, Tween 80 (Sigma Aldrich, USA).

\section{Methods}

\section{Extraction of cassava starch}

Cassava starch was extracted in Pharmaceutical Technology laboratory, University of Nigeria, Nsukka. The tubers of Manihot utilissima (cassava) was peeled and reduced into small pieces. The reduced pieces of cassava tubers were soaked in distilled water for $48 \mathrm{~h}$. After, it was washed and soaked in $0.1 \mathrm{M}$ sodium metabisulphite solution for $24 \mathrm{~h}$. Thereafter, the metabisulphite solution was washed off and pieces of cassava tubers ground/ blended to a pulp. The cell debris was removed by passing the slurry through a muslin cloth of $150 \mu \mathrm{m}$ aperture sieve size, with occasional passage of water for effective filtration. The starch was then allowed to settle and the supernatant decanted. The starch was suspended in 0.I N potassium hydroxide solution for $12 \mathrm{~h}$.
The solution was washed off completely and the starch was also suspended in 0 .I $\mathrm{N}$ sulphuric acid solution for $12 \mathrm{~h}$. The solution was effectively removed/ washed off and the settled starch washed with distilled water to remove impurities (e.g cyanide), tested for sulphates/sulphites, and dried at $40{ }^{\circ} \mathrm{C}$ for $6 \mathrm{~h}$. The extracted starch was identified using established protocols.

\section{Preparation of chlorpheniramine transdermal patches}

Varying concentrations of HPMC, cassava starch, and PEG 4000 were employed in the formulation of chlorpheniramine transdermal patches. Chlorpheniramine, propylene glycol and Tween 80 were used as fixed amounts. For the different batches $(\mathrm{A}-\mathrm{H})$, different quantities of the materials were weighed and measured as shown in Table 1.

The cassava starch and HPMC were mixed in a $250 \mathrm{ml}$ beaker dispersed in water (heated to $60^{\circ} \mathrm{C}$ ) and stirred to obtain mucilage. It was further diluted with $20 \mathrm{ml}$ of water. Propylene glycol, PEG 4000, Tween 80 and chlorpheniramine were dispersed in $10 \mathrm{ml}$ of water, stirred and then added to the mucilage. The mucilage was diluted to $50 \mathrm{ml}$ by making up with water, stirred and poured into a petri dish. The formulations were allowed to dry at room temperature after which they were stored for further use.

Table 1: Formulation of different patches

\begin{tabular}{lllllllll}
\hline Materials & Batch & Batch & Batch & Batch & Batch & Batch & Batch & Batch \\
& A & B & C & D & E & F & G & H \\
\hline Chlorpheniramine & $176 \mathrm{mg}$ & $176 \mathrm{mg}$ & $176 \mathrm{mg}$ & $176 \mathrm{mg}$ & $176 \mathrm{mg}$ & $176 \mathrm{mg}$ & $176 \mathrm{mg}$ & $176 \mathrm{mg}$ \\
Cassava starch & $1000 \mathrm{mg}$ & $200 \mathrm{mg}$ & $200 \mathrm{mg}$ & $600 \mathrm{mg}$ & $600 \mathrm{mg}$ & $200 \mathrm{mg}$ & $466.7 \mathrm{mg}$ & $320 \mathrm{mg}$ \\
HPMC & $1600 \mathrm{mg}$ & $2400 \mathrm{mg}$ & $1600 \mathrm{mg}$ & $2000 \mathrm{mg}$ & $1600 \mathrm{mg}$ & $2000 \mathrm{mg}$ & $1866.7 \mathrm{mg}$ & $2040 \mathrm{mg}$ \\
PEG 4000 & $200 \mathrm{mg}$ & $200 \mathrm{mg}$ & $1000 \mathrm{mg}$ & $200 \mathrm{mg}$ & $600 \mathrm{mg}$ & $600 \mathrm{mg}$ & $466.7 \mathrm{mg}$ & $440 \mathrm{mg}$ \\
Propylene glycol & $1 \mathrm{ml}$ & $1 \mathrm{ml}$ & $1 \mathrm{ml}$ & $1 \mathrm{ml}$ & $1 \mathrm{ml}$ & $1 \mathrm{ml}$ & $1 \mathrm{ml}$ & $1 \mathrm{ml}$ \\
Tween 80 & $0.2 \mathrm{ml}$ & $0.2 \mathrm{ml}$ & $0.2 \mathrm{ml}$ & $0.2 \mathrm{ml}$ & $0.2 \mathrm{ml}$ & $0.2 \mathrm{ml}$ & $0.2 \mathrm{ml}$ & $0.2 \mathrm{ml}$ \\
\hline
\end{tabular}

\section{Characterization of transdermal patches}

\section{Fourier transform infrared spectroscopy (FT-IR)}

FT-IR was used to investigate any chemical interaction between chlorpheniramine maleate and transdermal patch excipients. Sufficient quantities of pure chlorpheniramine maleate, HPMC, cassava starch, polyethylene glycol 4000 and the formulated transdermal patches were scanned over a wavelength range of 4000 to $650 \mathrm{~cm}^{-1}$ at a resolution of $4 \mathrm{~cm}^{-1}$ in a FT-IR instrument (Agilent Technologies, USA). The system was operated in the transmission mode. Samples were placed on the sample stage and $100 \mathrm{~N}$ force applied for scanning.

\section{Physical appearance and properties}

All the formulated patches were inspected for clarity, colour, and smoothness. Also other organoleptic properties such as odour was also observed.

\section{Folding endurance and percentage elongation break test}

Folding endurance of patches/ films was determined manually by folding a $1 \mathrm{~cm}^{2}$ strip of each patch repeatedly at the same place on the patch until a breaking point is reached.

The number of times that the patch was folded at the same place without breaking or cracking was taken as the value for the folding endurance.

The percentage elongation break was determined by recording the length just before the break point, the percentage elongation can be determined from Equation 1:

$$
\text { Elongation } \%=\frac{L_{1}-L_{2}}{L_{2}} \times 100 \text {--------------------1 }
$$

Where $L_{1}$ and $L_{2}$ are the final and initial lengths of each strip.

\section{Percentage moisture uptake and loss of patches}

The percentage moisture uptake of the patches was determined using static methods involving saturated salt solutions. For moisture uptake, weighed patches were placed in desiccators containing $100 \mathrm{ml}$ of saturated solution of potassium chloride (84\% relative humidity $\mathrm{RH}$ ). At $24 \mathrm{~h}$ intervals for 4 days, the patches were removed and weighed.

The percentage moisture uptake was calculated as one hundred times the ratios of the difference between final and 
initial weights to the initial weights of the patches (Equation 2):

Percentage moisture uptake $=\frac{\text { Final weight }- \text { Initial weight }}{\text { Initial weight }} \times 100--2$

For percentage moisture loss, the weighed patch samples were kept in a desiccator containing $20 \mathrm{~g}$ of anhydrous calcium chloride. At $24 \mathrm{~h}$ intervals for 4 days, the patches were removed and weighed repeatedly. The percentage moisture loss was calculated from the difference between initial and final weight with respect to initial weight as presented in Equation 3:

Percentage moisture loss $=\frac{\text { Initial weight }- \text { final weight }}{\text { Initial weight }} \times 100----3$

\section{Ex vivo skin permeation studies}

Ex vivo skin permeation studies was performed using a magnetic stirrer-beaker assembly. The patches were sandwiched between two layers of the excised skin while sealing the edges of the layers. The skin and the sandwiched patch were placed in a cylindrical basket which was suspended in a beaker containing $100 \mathrm{ml}$ of phosphate buffer saline ( $\mathrm{pH}$ 7.4). The assembly was fixed in a magnetic stirrer apparatus and the receptor medium continuously stirred using magnetic beads at $50 \mathrm{rpm}$, while the temperature was maintained at $37 \pm 1^{\circ} \mathrm{C}$. Samples were withdrawn at $1 \mathrm{~h}$ intervals for $5 \mathrm{~h}$ and analyzed for drug content using spectrophotometer at $252 \mathrm{~nm}$. The medium was replenished with equal volume of PBS, $\mathrm{pH} 7.4$, after each sample withdrawal. The amount of drug permeated per square centimeter of patches was plotted against time.

The permeation data was analyzed by determining the flux and permeability coefficient of the drug. The flux $\left(\mu \mathrm{g} \mathrm{cm}^{-2} \mathrm{~h}\right.$ 1) of chlorpheniramine maleate was calculated from the slope of the plot of the cumulative amount of chlorpheniramine permeated per $\mathrm{cm}^{2}$ of skin at steady state against time using linear regression analysis. The steadystate flux (J) was determined from the relationship in Equation 4:

$$
\mathrm{J}=\frac{d Q}{A d t}\left(\mu \mathrm{g} / \mathrm{cm}^{2} \mathrm{~h}\right) \text {------ } 4
$$

Where $Q$ indicates the quantities of substances crossing the rat skin, $A$ is the area of the rat skin exposed and $t$ is the time of exposure.

The permeability coefficients are obtained from the steadystate flux values using Equation 5:

$$
\mathrm{P}=J / C_{O}\left(\mathrm{~cm} \cdot \mathrm{h}^{-1}\right) \text {----------------5 }
$$

Where $\mathrm{P}$ is the permeability coefficient, $\mathrm{C}_{\mathrm{o}}$ is the initial drug concentration in the donor compartment and $\mathrm{J}$ represents the steady-state flux obtained from Equation $4 . \mathrm{C}_{o}$ is the concentration of drug in the patch.

\section{RESULTS AND DISCUSSION}

\section{Organoleptic properties of the transdermal patches}

The patches were smooth, opaque and odourless. The patches possess desirable physical attributes which would facilitate its general acceptance and use.

\section{Fourier transform infrared spectroscopy (FT-IR)}

The FT-IR (Figs. 1-6) showed that there was no drugexcipient interaction since all the bands in the spectra represented functional groups in the individual component. The FT-IR spectra of the components showed methyl, hydroxyl and ether bond stretching while amine bond stretch was also observed for chlorpheniramine. The spectra of formulated patches were also seen to have the bands representing these functional group.

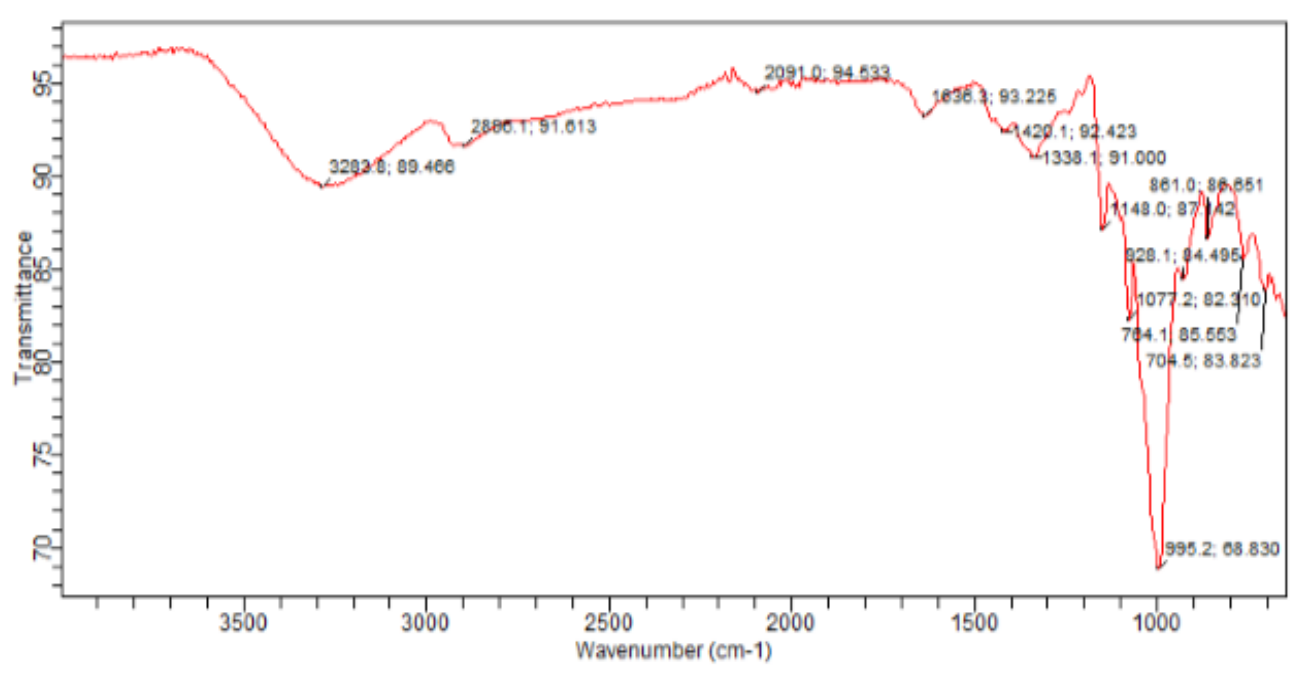

Figure 1: FT-IR Spectra for Cassava Starch 


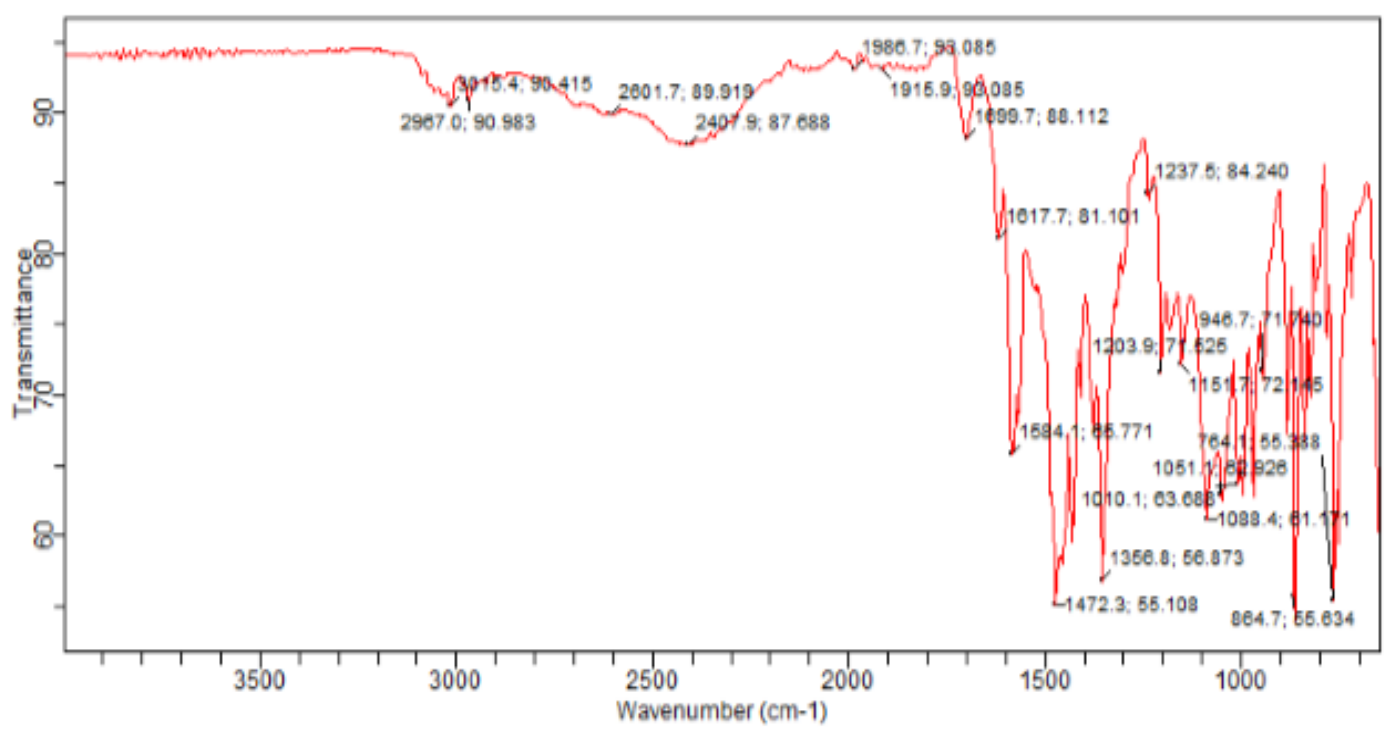

Figure 2: FT-IR Spectra for Chlorpheniramine

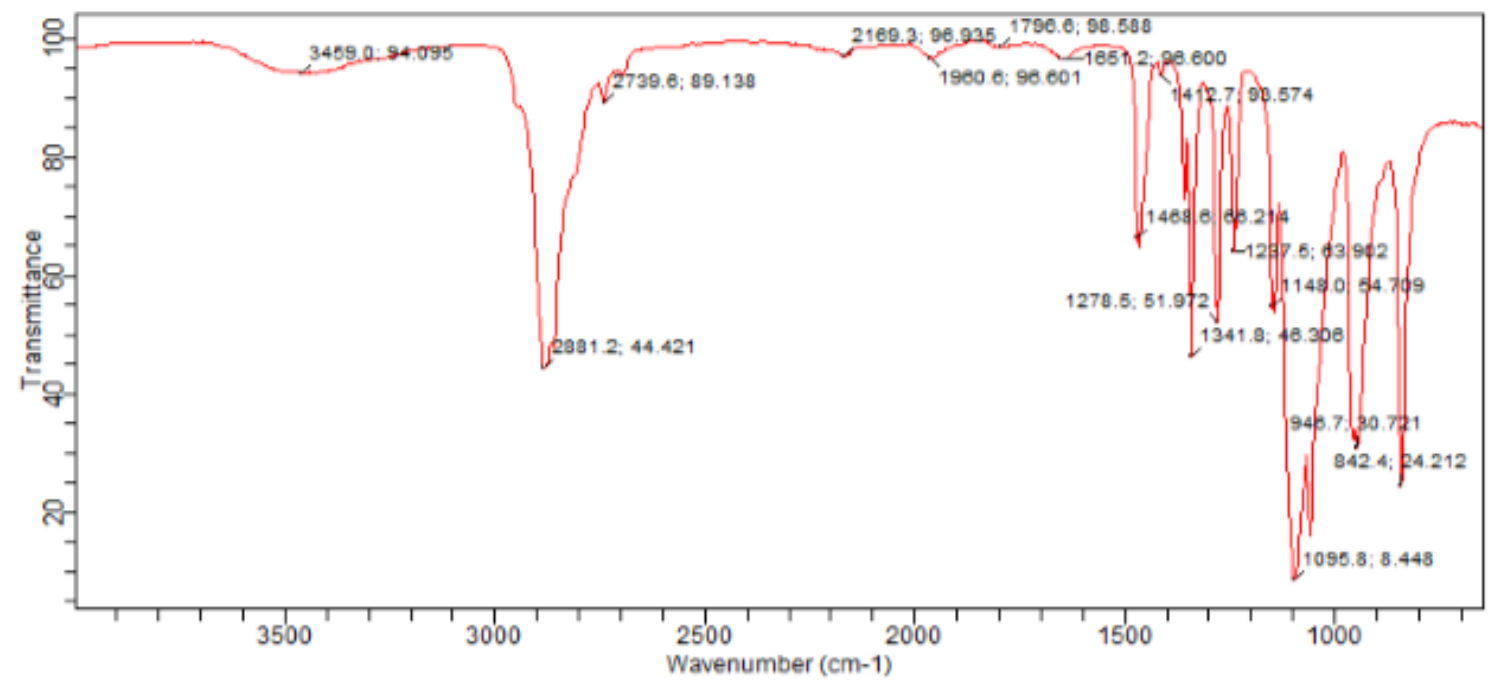

Figure 3: FT-IR Spectra for PEG 4000

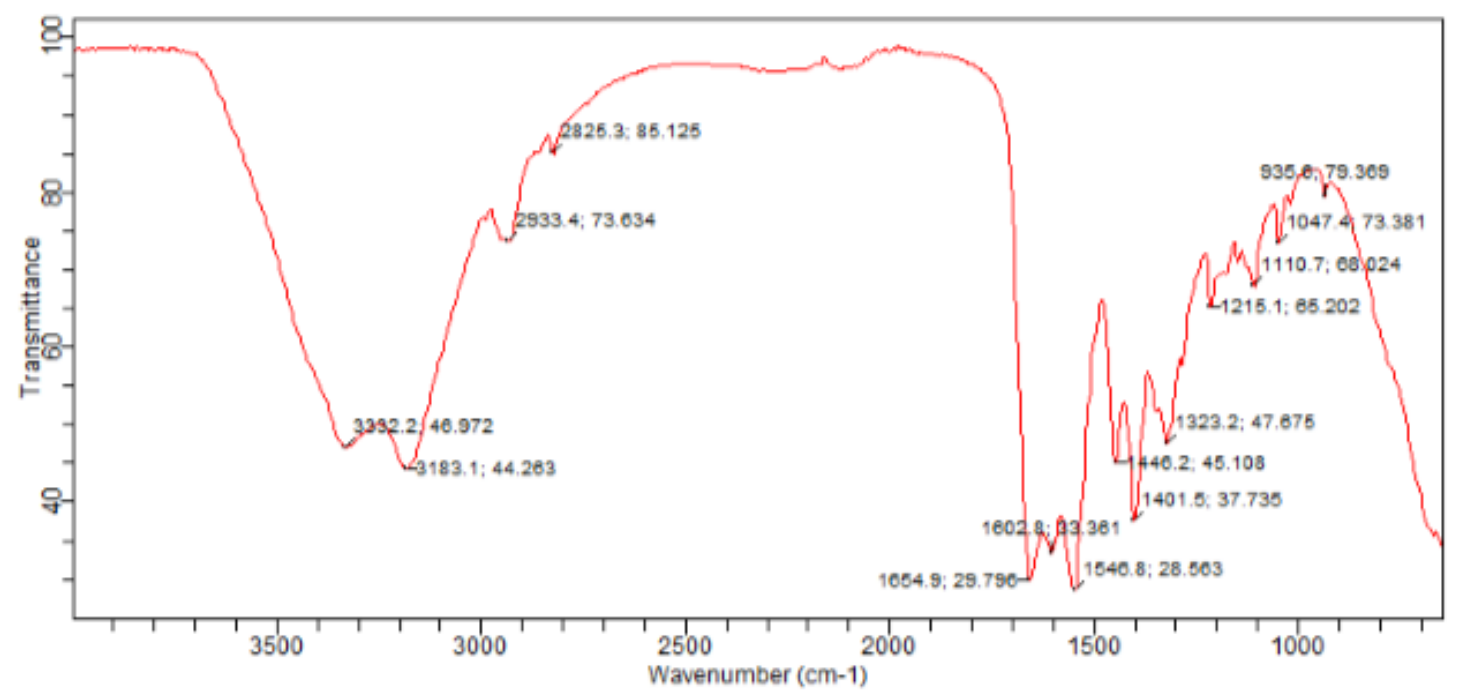

Figure 4: FT-IR Spectra for HPMC 


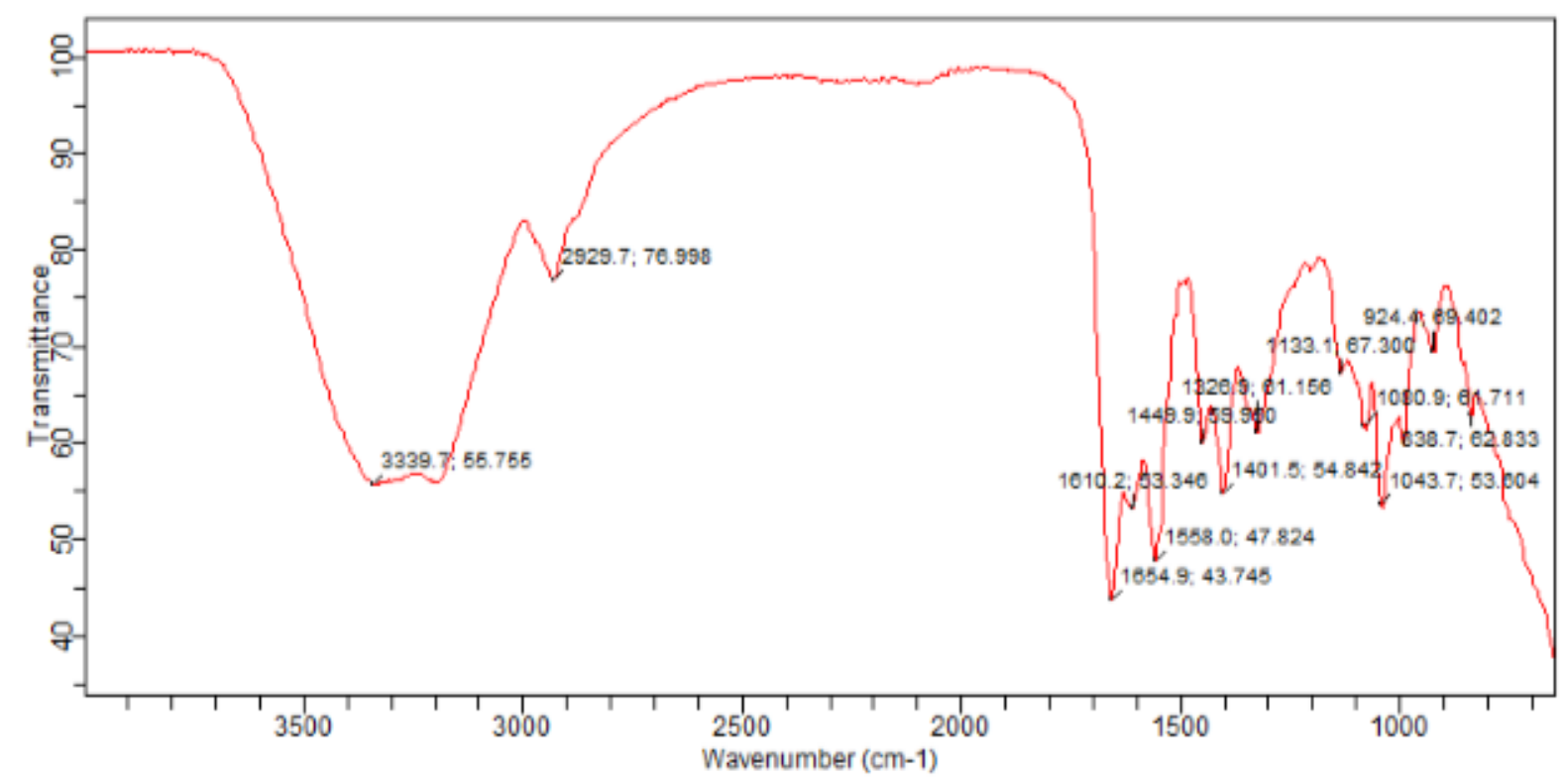

Figure 5: FT-IR Spectra for Batch A

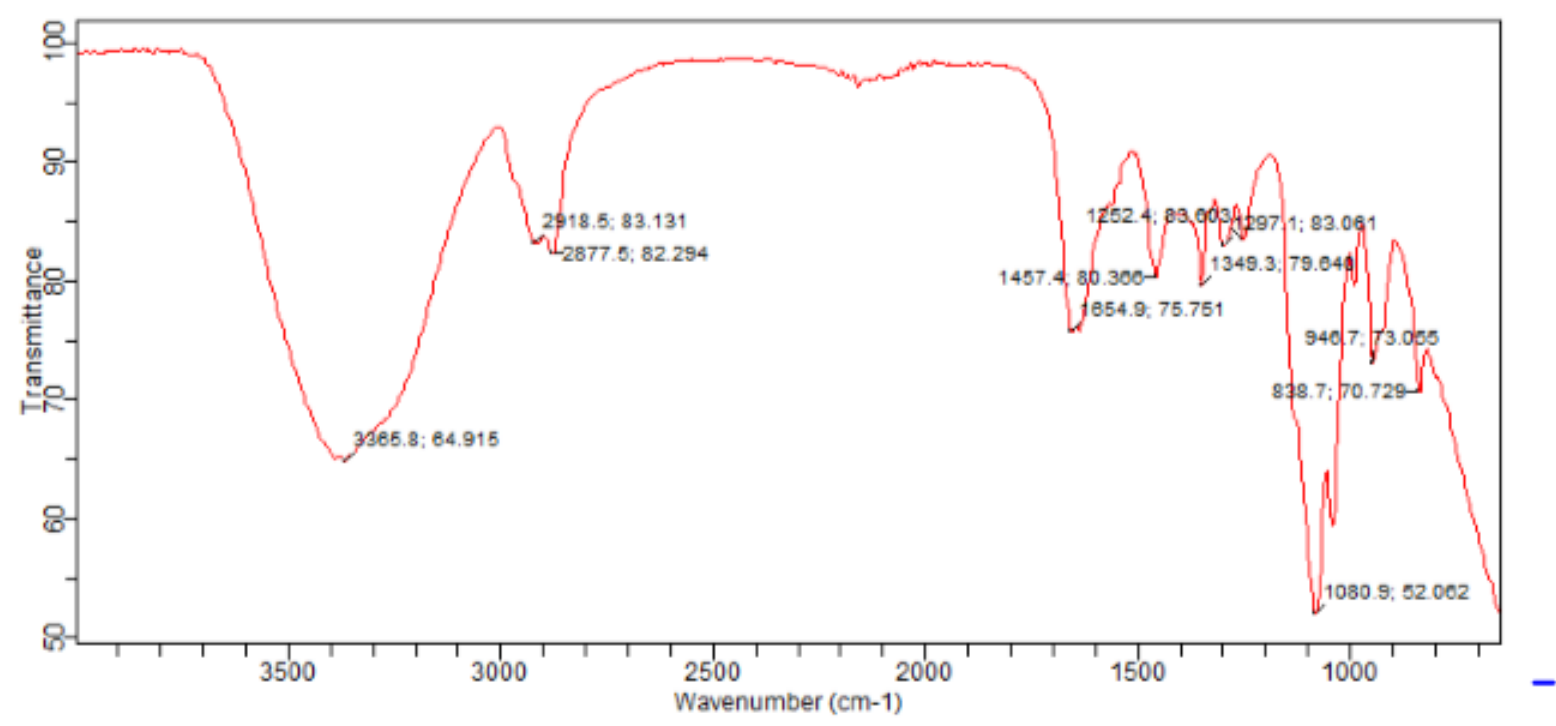

Figure 6: FT-IR Spectra for Batch F

\section{Folding endurance and breaking elongation}

The folding endurance of the patches were determined with patches C, E, F and G having the highest folding endurance of $>500$ and patch A showing the least folding endurance of 89 . Batches C, E, F and G have higher PEG concentration. This shows that differences in concentration of the constituents can affect the final mechanical property of the product. The combined effect of HPMC as film-former and PEG as plasticizer may have facilitated this flexibility attribute. Hydrophilic compounds such as polyethylene glycol has been used as plasticizers in starch-based films to improve the physico-mechanical and barrier properties of these products. The brittleness and rigidity of mixtures containing starch (after storage), usually facilitated by recrystallization of starch molecules, causes a major problem 5. The biodegradable PEG plasticizer may have occupied intermolecular spaces between polymer chains, changed the 3D-molecular organization, reduced the energy required for molecular motion and improved hydrogen bonding between chains. The results of folding endurance are presented in Table 2. The percentage elongation break test measures the ability of the formulated patches to withstand the mechanical stress of pull. The formulated patches $(\mathrm{A}-\mathrm{H})$ all showed elasticity on elongation.

\section{Percentage Moisture Uptake and Loss}

The percentage moisture uptake (Fig 7) with time (in days) of the formulated patches showed that patch $A$ had the highest uptake and patch $B$ had the least moisture uptake. Patch A with high concentration of cassava starch absorbed more moisture than other patches while batches $D$ and $B$ with high amounts of HPMC showed low moisture uptake probably because the HPMC had already entrapped and bonded relatively large quantities of water during production inhibiting further attraction of moisture. Moisture content would affect properties such as adhesion 
and stability (especially since moisture supports microbial growth which causes degradation). Physical integrity of the product would also be affected.

For moisture loss (Fig 8), patches B, D, F and $\mathrm{H}$ with higher HPMC concentration showed higher moisture losses. This is because it was relatively easier for these batches to loss water under dry atmosphere than to absorb more under high relative humidity.

Percentage moisture uptake and loss were mostly around 0$40 \%$ and $15-45 \%$, respectively. The nature and strength of bonding of all the constituents in the transdermal patches or films would affect the rate and extent of drug release from these automated devices.
Table 2: Folding endurance of the transdermal patches

\begin{tabular}{ll}
\hline Batch & Folding Endurance \\
\hline A & 89 \\
B & 230 \\
C & $>500$ \\
D & 100 \\
E & $>500$ \\
F & $>500$ \\
G & $>500$ \\
H & 200 \\
\hline
\end{tabular}

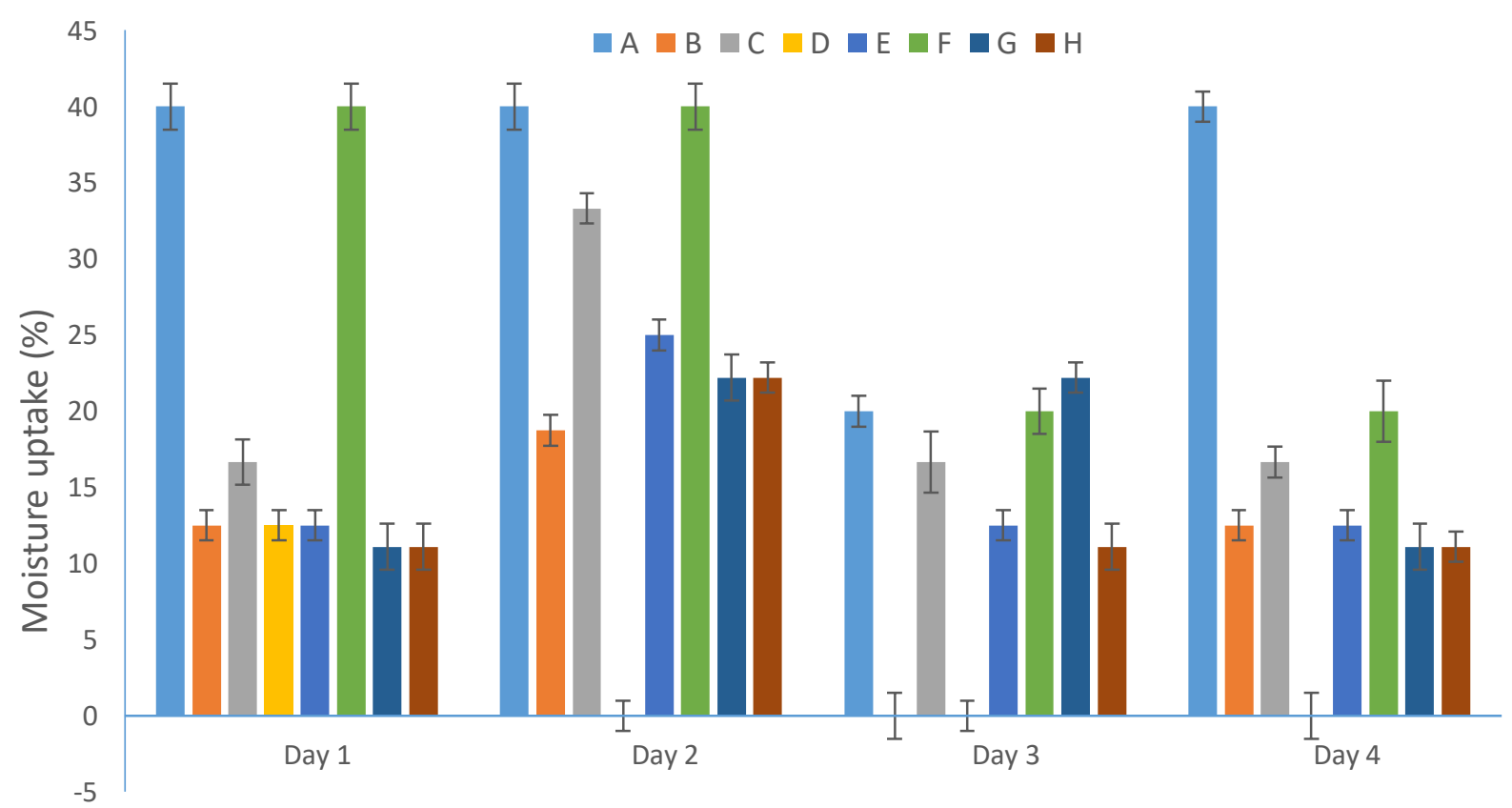

Figure 7: Moisture uptake profile of patches

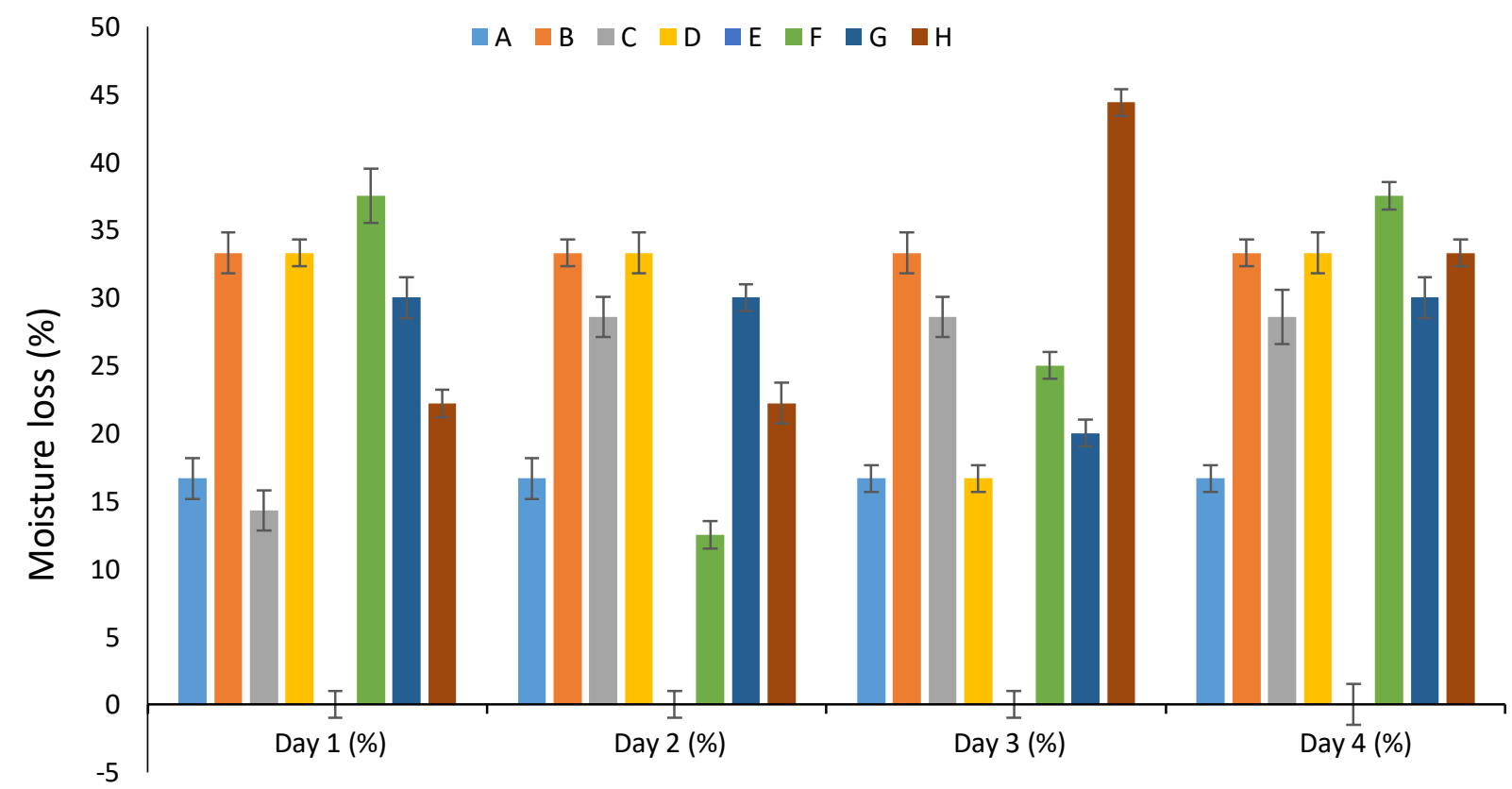

Figure 8: Moisture loss profile of transdermal patches 


\section{Ex vivo Permeation Studies}

From the results obtained (Fig. 9), batch G showed the highest chlorpheniramine permeation through the excised rat skin. This batch is at the centre point of the design of experiment and contains the variable components as follows; cassava starch $0.47 \mathrm{~g}$, HPMC $1.87 \mathrm{~g}$ and PEG 4000 $0.47 \mathrm{~g}$. This shows the need for a balance of these components and an optimal mixture is required for maximum permeation of chlorpheniramine. Batch E showed the lowest chlorpheniramine permeation and independent variables present are cassava starch $0.6 \mathrm{~g}$, HPMC $1.6 \mathrm{~g}$ and PEG 4000 0.6g. The result showed that improved permeation may be achieved if the difference between HPMC and either or both of cassava starch or/and PEG 4000 is more than $1 \mathrm{~g}$ or a factor of 2.67. Most of the films showed a sustained, steady release and permeation of chlorpheniramine. The use of HPMC created a network that is highly hydrophilic allowing drug release. The responses obtained showed that combinations around the centre point of the centroid design space produced films with improved drug release and permeation. It has been typically observed that addition of hydrophilic component to an insoluble filmformer usually improves the drug release rate ${ }^{6}$. Usually the dissolution of the aqueous soluble fraction of the film or patch facilitate drug release and permeation and may create channels or pores which decrease mean diffusion path length of the drug molecule being released into dissolution medium ${ }^{7}$.

Batches B and D with relatively high HPMC and low PEG showed a rising permeation profile probably because the lower amount of plasticizer allowed gradually increasing release and permeation. The transdermal patches exhibited controlled drug delivery for the release and permeation of low dose of chlorpheniramine through the excised rat skin over a prolonged period of time. Furthermore the metered dose released over time showed that similar transdermal profile can be achieved for infant dose.

Flux was obtained as slope of linear relationship between amount of drug permeated per unit surface area and time. The flux and permeability coefficients are shown in Table 3.

The range of these important permeation parameters are as follows; Flux was $7.40-15.93 \mu \mathrm{g} / \mathrm{cm}^{2} \mathrm{~h}$ and permeability coefficient was $0.000561-0.001207 \mathrm{~cm} / \mathrm{h}$. These data reflect the possibility of applying the formulation for tailored infant doses. The unique nature of the modified ex vivo study with film/patch sandwiched between skin surfaces allowed diffusion of drug to occur from the two sides of the film/patch with increased initial drug release. The values of the steady state flux or rate of drug permeation showed that the transdermal system may be valuable in minimizing the sedating effect of the drug by only providing small gradual increments in systemic drug concentrations. The presence of polysorbates in the formulation enhances drug permeation by opening epidermal pores and tight junctions. Some surface-active agents have been shown to affect tight junction permeability ${ }^{8}$. Previous studies have shown that mixtures of hydrophilic polymers and cassava starch can form suitable film-formers for improved transdermal drug delivery ${ }^{9}$ and HPMC have been effectively used to formulate transdermal films of low dose drugs 9,10 .

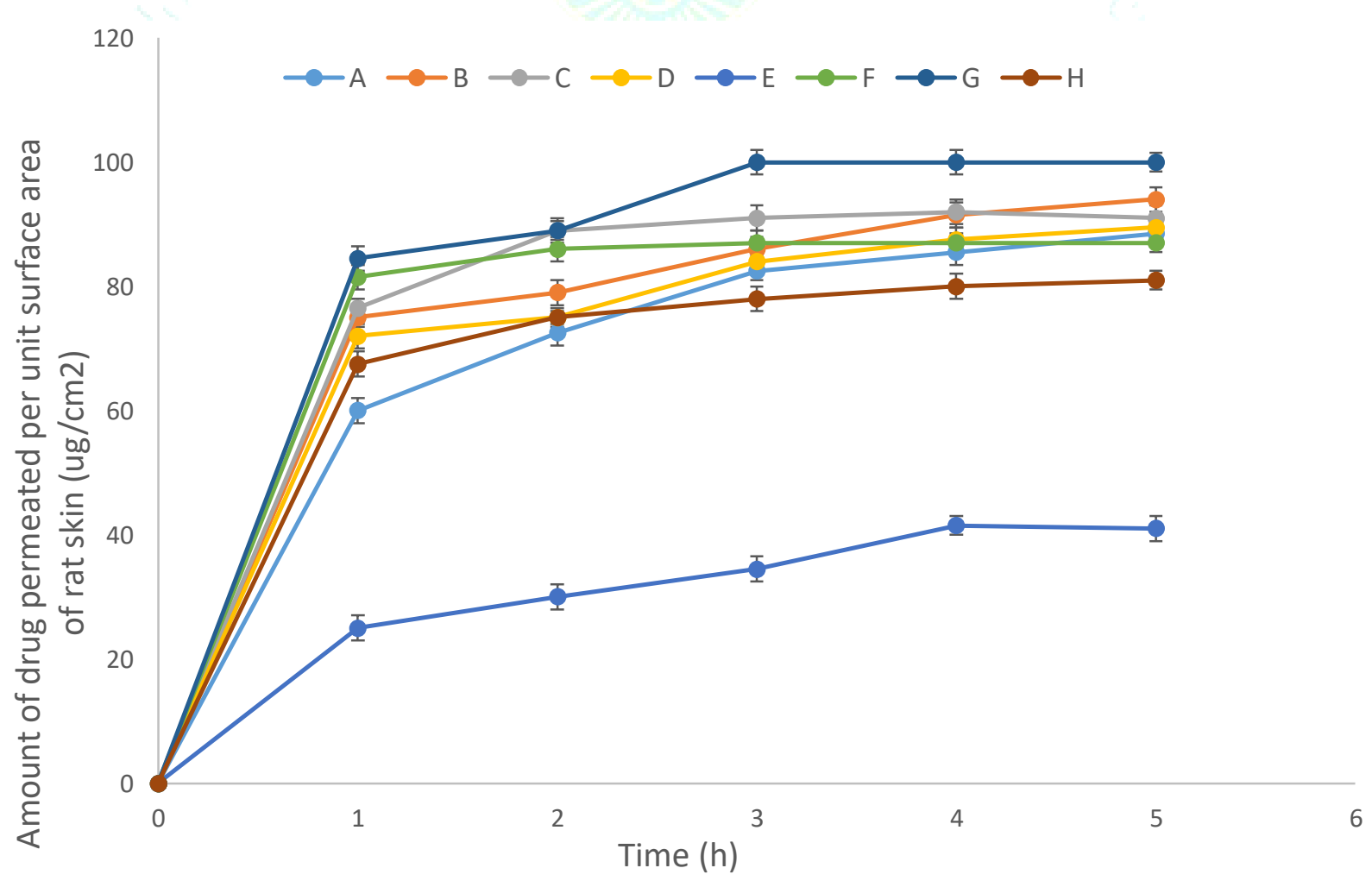

Figure 9: Chlorpheniramine permeation profile 
Table 3: Flux and Permeability Coefficient values for chlorpheniramine transdermal films

\begin{tabular}{lll}
\hline Batches & Flux $\left(\mu \mathrm{g} / \mathrm{cm}^{2} \mathrm{~h}\right)$ & Permeability coefficient $(\mathrm{cm} / \mathrm{h})$ \\
\hline A & 15.11 & 0.001145 \\
B & 15.04 & 0.001139 \\
C & 14.39 & 0.001090 \\
D & 14.37 & 0.001089 \\
E & 7.40 & 0.000561 \\
F & 12.93 & 0.000980 \\
G & 15.93 & 0.001207 \\
H & 12.73 & 0.000964 \\
\hline
\end{tabular}

\section{CONCLUSION}

The transdermal route has been shown to be effective, noninvasive means for the administration of Chlorpheniramine in allergy-related conditions. Hypromellose and cassava starch function effectively as film formers for the formulation of the transdermal patches. Different combinations of materials produce patches with varied physical, mechanical and drug permeation properties. Transdermal patches can be effectively used to deliver controlled doses of chlorpheniramine through the skin for systemic actions for prolonged duration and may be useful in Paediatric Medicine.

\section{Conflict of Interest}

The authors declare that they have no conflict of interest

\section{Funding}

This research was funded by Tertiary Education Trust Fund (TETFund; IBR/ 2015) of the Federal Government of Nigeria

\section{REFERENCES}

[1] Simons FER, Luciuk GH, Simons KJ, Pharmacokinetics and efficacy of chlorpheniramine in children. The Journal of Allergy and Clinical Immunology 1982; 69(4):376-381

[2] Rumore MM, Clinical Pharmacokinetics of Chlorpheniramine, Annals of Pharmacotherapy, 1984; 18 (9):701-707
[3] Kumar A, Pullankandam N, Prabhu SL, Gopal V, Transdermal drug delivery: an overview, Int. J Pharm Sci. Review Res., 2010; 3(2): 49-54.

[4] Divya A, Rao MK, Gnanprakash K, Sowjanya A, Vidyasagar N, Gobinath M, A review on current scenario of transdermal drug delivery system, Int. J Res. Pharm Sci., 2012; 3(4):494-502

[5] Vieira MGA, da Silva MA, dos Santos LO, Beppu MM, Naturalbased plasticizers and biopolymer films: A review, European Polymer Journal, 2011; 47(3):254-263

[6] Bodmeier R, Paeratakul O. Theophylline tablets coated with aqueous latexes containing dispersed pore formers. J. Pharm. Sci. 1990; 79:32.

[7] Rao PR, Reddy MN, Ramakrishna S, Diwan PV, Comparative in vivo evaluation of propranolol hydrochloride after oral and transdermal administration in rabbits, Eur. J. Pharm. Biopharm., 2003; 56:81-85

[8] Anderberg EK, Artursson P, Epithelial transport of drugs in cell culture 8 . Effects of sodium dodecylsulfate on cell membrane and tight junction permeability in human intestinal epithelial (Caco-2) cells, J. Pharm. Sci., 1993; 82:392-398.

[9] Agubata CO, Ottah OG, Development, characterization and ex vivo studies of transdermal patches for the delivery of diazepam using hypromellose, polyvinyl alcohol and cassava starch composite polymers, Journal of Pharmaceutical Development and Industrial Pharmacy, 2019; 1(1):1-9

[10] Singh A, Bali A, Formulation and characterization of transdermal patches for controlled delivery of duloxetine hydrochloride, Journal of Analytical Science and Technology, 2016; 7:25. DOI 10.1186/s40543-016-0105-6 